\title{
Actual trends of architectural forms and graphics in the costume design context
}

\author{
Larisa Klimova $^{1, *}$, Marina Plotnikova $^{2}$ \\ ${ }^{1}$ Isop (branch) DSTU, 147, Shevchenko str., 346500, Shakhty, Russia \\ ${ }^{2}$ Don State Technical University, 1, Gagarin sq., 344000, Rostov-on-Don, Russia
}

\begin{abstract}
This article is devoted to the study of the graphic trends and design activities' relationship for a costume designer with modern architectural forms, as a source of inspiration and style formation for these subject-spatial creativity areas. The purpose of the article is to identify the specifics of the associative trends' relationship in modern costume design with architecture and graphics. Identification of this specificity will help in establishing the relevant interdisciplinary connections in design education. To achieve this goal, the authors set the following tasks: 1) analysis of modern trends in costume formation based on identifying the features of the architectural forms' influence on the modern costume design; 2) analysis of the general structural and graphic solutions between the modern presentation of architectural forms in the costume design by means of its graphic content. The authors proceed from the idea of the modern phenomena interaction in costume design, its graphics and architectural forms. In the analysis of the modern graphics and architectural forms' main features in the conceptual solution to the costume design, common features of interaction are revealed. Changes in the art and design activities in the direction of graphic symbolism and imagery are revealed on the example of modern trends in architecture. The results of the study on the introduction of interdisciplinary communications are tested in classes on design in the material's project implementation, special graphics and concepts in design.
\end{abstract}

\section{Introduction}

The cultural prerequisites for the design emergence are: abstraction of form; rejection of decor in favor of the simple geometric shapes; a change in the perception of the public under the influence of modernism towards the abstract morphogenesis aesthetics [1].

Design is a creative activity that combines the achievements of various fields of human knowledge and practice (sociology, art, design and technology, economics, politics, psychology and much more), and is aimed at designing the aesthetically perfect, highquality and popular products. According to N. Voronov, Yu. Shestopal, design is a special method, a special way to solve the problems by means of a new layout of the already known elements. Therefore, it is rather a psychological phenomenon, a special combinatorial orientation of thinking, allowing the designer to generate the ideas in the

\footnotetext{
${ }^{*}$ Corresponding author: k_larisssa@mail.ru
} 
field of his professional activity and transform the environment. Industrial design aims to create a "useful, universally convenient". The beauty nature category in design determines the special role of beauty "as one of the convenience elements in a natural way". Such beauty is "the background for the main subject's function and for the person communicating with the subject" [2].

There is an intersection area of the design types. The environment design combines the interior and exterior, shop windows, exhibitions, retail space, holiday design. This is the sphere of interaction between a human and the environment, which, like fashion, can be attributed to the subject and communicative design, as it is not just a creation of clothing, but the self-presentation of a person. It cannot be denied that in all dimensions of design, the main impact on its development is exerted not only in technology, economics, but also in the art and design activities, including architecture [3].

We can say that the design culture that captures all human activity spheres - from architecture to commodities and the means of communication is emerging. [3].

\section{Materials and methods}

To achieve the study goal, the authors use the methods for identifying the correlation between architectural forms and modern design, methodological procedures for the comparative analysis of practical design activities, synthesis, generalization, principles of historicism and consideration specificity.

On any local topic of research or design - a specific architectural object, costume model - the designer forms his own unique "toolbox" - a specific subject and method of his own work. Such "concreteness" arises as a result of the general methodological premises' intersection of research and real tasks. In other words, based on the assigned design tasks, the architect / designer can apply one or several general design methods: figuratively associative, analytical, analog, combinatorial, historical-genetic, art-structural, synthesis method, synergetic and others, introducing his own author's intuition, which gives an interesting artistic and design result [4].

\section{Discussions and Results}

The costume is designed based on the study and use of various creative sources. One of the main and relevant, source of inspiration in the light of modern trends for the work of costume designers is the graphics and architectural forms that have a great impact on the aesthetic culture of the era, people's tastes, shaping their beauty sense.

Classical and contemporary works of art (architecture, painting, graphics, etc.) inspire the costume designers to create fashion collections - from couture and ready-to-wear to the mass market. Models that reflect the high standard categories of costume and are highly artistic examples of style, form, decor are themselves the art objects and are exhibited at museums and exhibitions as the art works. Each major state art museum has a collection of national, secular or modern costume. Fashion professionals, participants in the public talk "Art \& Fashion: Romance of Love", dedicated to the fashion and art union, note the similarity of the process of creating the ideas and philosophy of the clothing collection and the object of contemporary art. It cannot be denied that fashion is a part of a consumer culture, momentary and this duality creates interesting collaborations and alliances. This is more relevant to ready-to-wear, while couture collections are designed as close as possible to the works of art [5].

Between costume and architecture, there is a formative and stylistic connection, which is expressed in the unity of the imaginative solution, the commonality of silhouettes, basic 
proportions. In addition to form-forming features and tectonics, the costume and architecture are related by the materials' texture, which has a rather aesthetically expressive and style-forming meaning. Many designers and fashion designers received architectural education - K. Balenciaga, P. Cardin, D.F. Ferre, T. Ford. This is reflected in their collections, which are distinguished by ideal proportions, the polished rhythm of lines and forms. Often these laconic and expressive forms are devoid of decoration, as they are very self-sufficient for creating an image. Other world designers, not being professional architects, turned to the architectural structures as emotional sources and reference examples of design culture: G. Chanel, P. Balmen, K. Dior, R. Cavakubo and others. The lines' nature, the degree of their emotional tension, the rhythm and meter of modern avantgarde architecture can be reflected in the plastic and rhythm of the design of the designed costume. Figure 1 presents the examples of the architecture and fashionable costume's relationship [4].
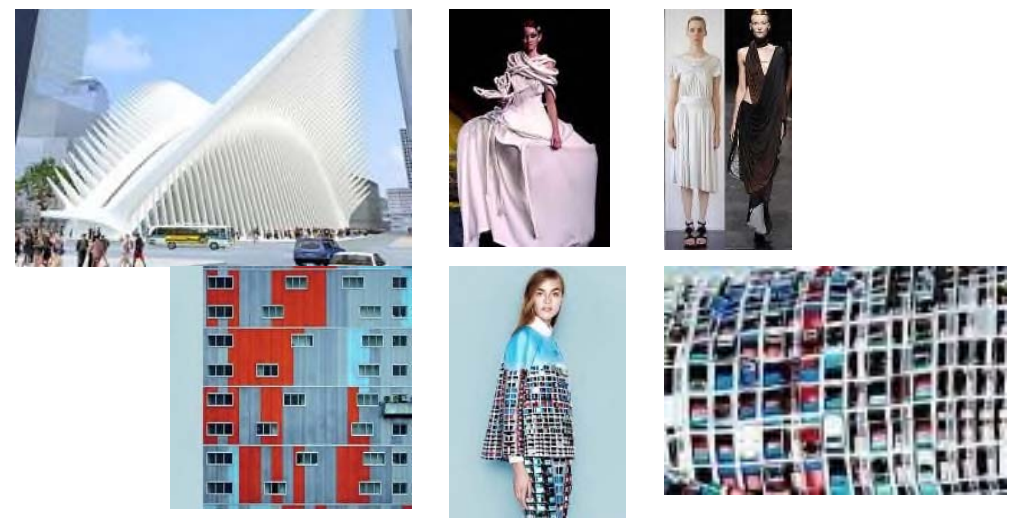

Fig. 1. The relationship of costume design with avant-garde architecture.

Quite often, the paintings and graphic works of artists are directly or indirectly embodied in fashionable images and structurally-decorative solutions of the form (Figure 2 - 4) [6].

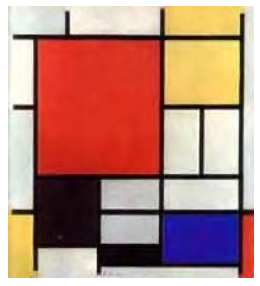

Fig. 2. P. Mondrian, 1921.

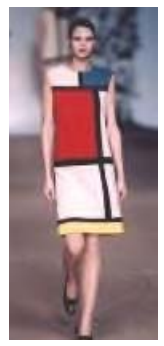

Fig. 3. Dress I. Saint Laurent, 1961.
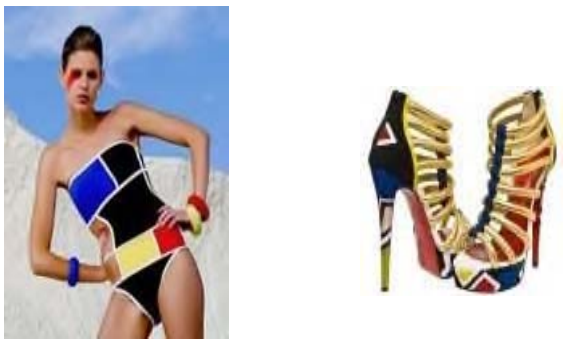

Fig. 4. Model of a modern bathing suit and accessories, 2015

Most often, fashion designers and the designers, inspired by the picturesque and graphic canvases of their colleagues, use them as patterns to create prints on fabrics. One of the first was: E. Schiaparelli, who was friends with the surrealists, and C. Dior, who used the images of impressionist paintings to create "pictorial" fabrics for the models in the "new bow" style [4]. 
Modern artists are actively entering into co-creation (collaboration) and alliances with painters and graphic artists. An example of the painting synergistic combination, Russian costume and fashion can serve as models of the ISO \& P (branch) DSTU collection of the student E. Zhirnova, (the tutor is the Union of Designers member of the Russian Federation, associate professor T. A. Mitrokhina) in a collaboration with the artist O. Gurenkov, who allowed the use of illustrations his work to create prints on fabrics for the collection (Figure $5,6)$.

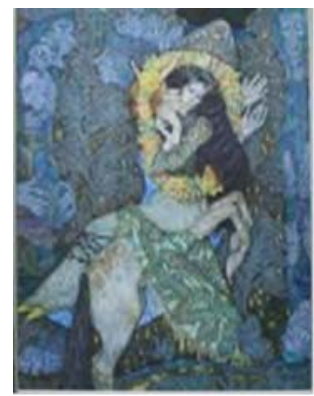

Fig. 5. O. Gurenkov "Veles and Vila" [3].

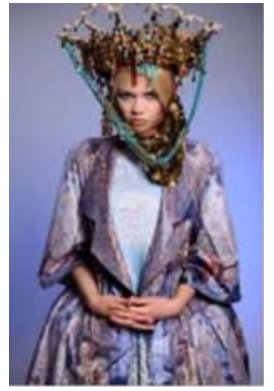

Fig. 6. Model from the collection of E. Zhirnova.

The famous "grandmother of the Japanese avant-garde" - Yayoi Kusama - made a large and very original project for Louis Vuitton showrooms in Singapore, which is a good example of the collaboration co-creation of a famous brand and a famous artist for the specified region (Figure 8) [7].
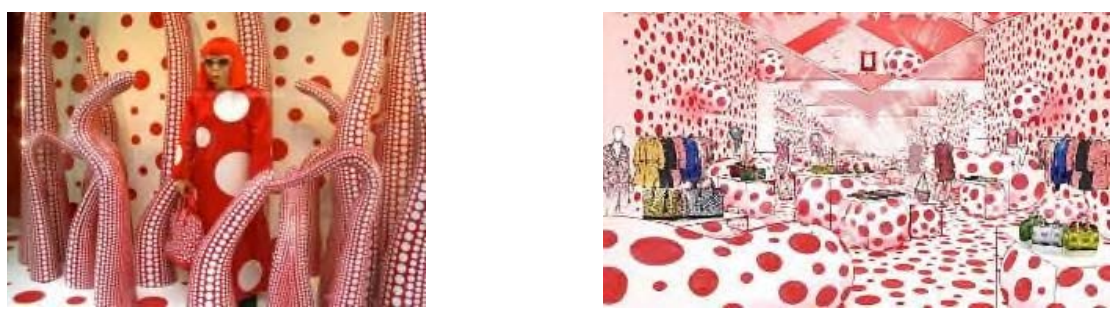

Fig. 7. Design by Yayoi Kusama for the Louis Vuitton Fashion House.

In the classical era, architecture dominated among all the arts, so all great art styles are imbued with similar proportional, rhythmic and plastic solutions. This relationship is visible in the twentieth century, and today, but, according to scientists, during modernism, design, in particular architecture, has given the way to industrial design [2].

The artistic practice of modern design starts being built on a fundamentally new concept of culture, its expressive styles, which, in turn, is caused by changes in ideology, value system and interpersonal relations in society. As a result, the subject-spatial environment of people's environment, which is a product of their project activity, their idea of harmony and beauty, is conceptually transformed [8].

So, today the project activities of a graphic designer often become a source of inspiration for other subject-spatial creativity areas. Graphic design least of all gravitates to technological circumstances, therefore, started being acquired a more noticeable figurative, iconic and visual nature. The development of computer technology enhances the qualities of lightness, mobility and technological freedom. It has become customary for a graphic designer to operate with information and iconic images of the information society.

The work of graphic designers is becoming increasingly prominent figurative, iconic and visual-graphic nature. The interaction between a thing and a person today is 
increasingly turned to the "interface". The project activities' interface is growing, becoming a graphic "ease" goes into various types of architectural and design creativity. Graphic design more and more penetrates the environment design, costume design, influencing fashion trends, bewitching with the original author's graphics of prints (Figure 8,9).
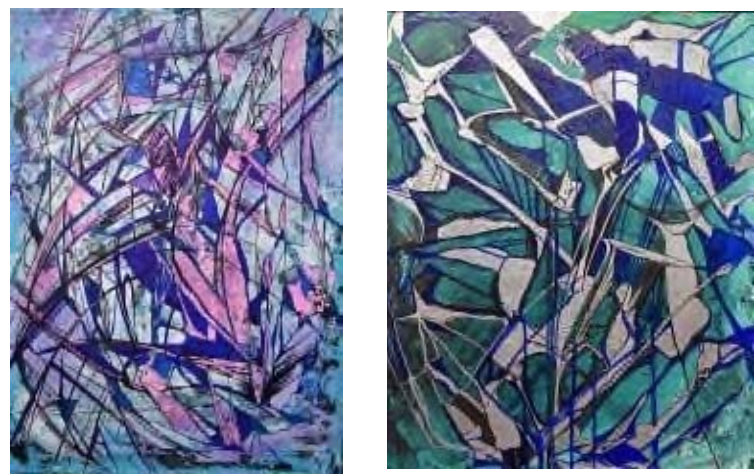

Fig. 8. Author's graphics Member of the DU of the Russian Federation M.G. Plotnikova "Dance of the Rays", "Meeting Lines".

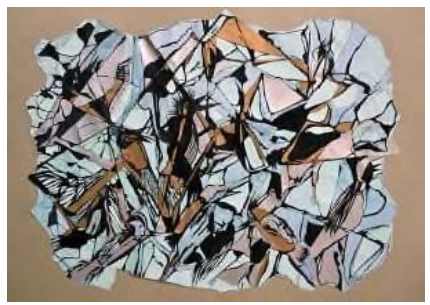

Fig. 9. Author's graphics of a member of the DU of the Russian Federation M.G. Plotnikova "Twitter".

The educational process in modern conditions of constantly expanding scientific and technological progress is aimed at obtaining the professional and integrated thinking. Design in projects becomes an educational discipline that initiates a continuous search for the integration mechanisms and methods [7].

The modern method among the basic principles of teachers' work is to involve practicing designers in the pedagogical process, since experience, personal intuition, the desire to study and apply the new technologies and current trends in the educational process are especially important for mastering the profession. One of the important components of an educational project is the introduction of modern trends in graphics, design and fashion into educational design tasks [10].

Fashion, responding to the most striking events of the city's public life (exhibitions, creative projects, street art festivals), actively masters all types of graphic art. Fashion houses around the world are inspired by popular graphics in the environment. This area is a wide field of activity for research.

Museums are currently seeing a significant increase in the number of visitors. This is a great trend in demand in postmodern society. But real art no longer needs to be sought only in the museum: contemporary street art artists create masterpieces right on the streets of our cities. Street art includes: graffiti, post-graffiti, street art, mural, wall painting. In turn, these various types of graphics are used in urban space and will inevitably change its appearance, influencing the socio-cultural situation. The area of such painting most often occupies the entire wall of a multi-storey building and becomes a part of the urban landscape. Murals are performed by artists on the walls of city houses, fences and have a highly artistic effect. 
Thus, street art, according to Yu. Pogosov, and the authors completely agree with him, is associated with the "understanding and experiencing" of urban space and constant interaction with it [11].
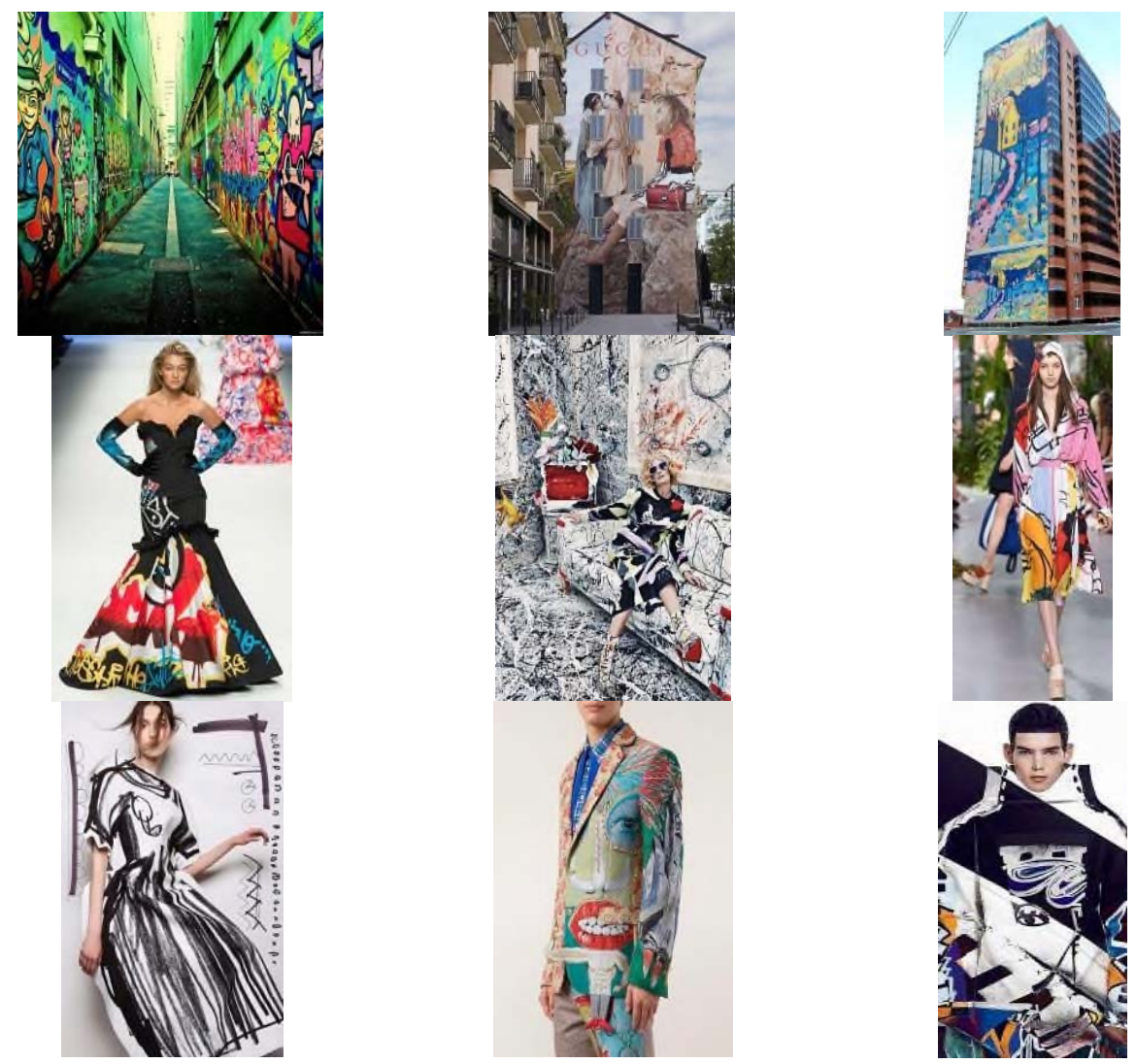

Fig. 10. Street art in architecture, graphics and costume.

For structural analysis, about 500 costume models were investigated, including the accessories posted on the electronic resource VOGUE.RU, which is one of the main professional websites on fashion and costume design in the world. The analysis showed the dependence of printing on materials on the following factors:

- selection of a defining idea based on the fashion trends / social order analysis;

- the formation of an artistic and structural idea related to the image and composition:

- linear-structural connection of a figure with the plastic form of a product;

- selection of materials for clothing;

- product terms in use

- selection of printing techniques,

- tools and accessories for printing on fabric

- test painting;

- the figure emphasizes the plastic form of a product, contrasts or contradicts it, creating a nuanced or (chaotic) deconstructive dynamics within the silhouette;

- all kinds of materials are used: natural and synthetic fabrics, lace, leather, fur, mesh, etc.;

- ink painting, printing, applying paint on a damp cloth, drawing with liners, spray, inkjet, embroidery, collage and others; 
- refinement of composition, color and technology.

Figure 10 presents the works reflecting the features of street graphics in the architecture and costume design $[2,5]$.

\section{Summary}

A comparative analysis of the interactions and interdisciplinary connections of project cultures and the modern design trends' specifics showed that they share common graphic ideas that penetrate each other, which, in the interaction course, give rise to new creativity. The presence of identified relationships helps in the development of new technologies and the use of original conceptual solutions.

The revealed moments of the costume design, graphics and architectural forms' interaction, made it possible to conclude about the positive impact of fashion trends that make the designer develop comprehensively in various areas of design activity. The practical results of the identified interdisciplinary relationships of project activities are used in design classes in the project material's implementation, special graphics and concepts in design.

The work "Meeting Lines" was published in the catalog for participating in the Spring Regional Exhibition of works by the artists of the Don, Novocherkassk. Graphic work "Twitter" received a diploma for participating in the international art project "Square +". The graphic work "Dance of the Rays" is on display at the Nate Art Project (Heritage. Vanguard. Partnership. Eurasian) organized by the Artistic Eurasian Union EURASIAN ART UNION.

\section{References}

1. S.M. Mikhailov, A.S. Mikhailova, The time of industrial design Sociocultural problems of design (Rostov-on-Don, 2008)

2. N. Voronov, J. Shestopal, Trend of the season: design, beauty, art (2020) http://tatlin.ru/articles/dizajn_krasota_iskusstvo

3. V.O. Pigulevsky, Antey 188(III), 8-9 (2013)

4. L.A. Klimova, T.A. Mitrokhina, All-Russian Scientific and Practical Materials. Conference "Russian Regions as Development Centers in the Modern Socio-Cultural Space” (Kursk, Southwestern State University, 2018)

5. Art\&Fashion, https://instyle.ru/lifestyle/culture/10-glavnykh-mysley-ob-iskusstve-imode-s-meropriyatiya-art-fashion-pri-podderzhke-instyle

6. A.A. Kuleshov, Costume design: theory, practice, education, monograph (Mines, ISOiP (branch) of DGTU, 2015)

7. L.A. Klimova, T.M. Ramazanova, M.G. Plotnikova, Innovations in the design and design of objects of the fashion industry, monograph (Novocherkassk, Lik, 2018)

8. M.G. Plotnikova, Design of a thing: cultural-historical transformations. Abstract of dissertation for the degree of candidate of philosophical sciences (Rostov-on-Don, 2014)

9. K.A. Kukso, Aesthetics of street art. Sat articles (SPb, SPbGUPTD, 2018)

10. M.G. Plotnikova, Pedagogy of Art: electronic scientific journal 3 (2016) http://www.art-education.ru/sites/default/files/journal_pdf/plotnikova_110-114.pdf

11. I.G. Ponosov, Art and the city: graffiti, street art, activism (2016) 